\title{
SUGAR AND ACID CONTENT OF ORGANICALLY AND CONVENTIONALLY GROWN STRAWBERRY (FRAGARIA × ANANASSA)
}

\author{
Virág Mihálka ${ }^{1^{*}}$, Rita Székelyhidi ${ }^{2}$, Viktória Kapcsándi ${ }^{2}$ and Ildikó Király ${ }^{3}$ \\ 1 Department of Agriculture, Faculty of Horticulture and Rural Development, \\ John von Neumann University, Hungary \\ 2 Department of Food Science, Faculty of Agricultural and Food Sciences, \\ Széchenyi István University, Hungary \\ ${ }^{3}$ Department of Horticulture, Faculty of Horticulture and Rural Development, \\ John von Neumann University, Hungary \\ https://doi.org/10.47833/2020.2.AGR.042
}

\section{Keywords:}

Organic farming

Strawberry

Functional food

Health-promoting compounds

\section{Article history:}

Received 10 May 2020

Revised 20 May 2020

Accepted 25 May 2020

\begin{abstract}
In a series of experiments we investigate the effect of growing conditions on the quality of strawberry fruits. In the present article, carbohydrate and organic acid components of fruits grown under organic conditions versus conventional farming conditions were compared. Effects of two biostimulants licensed for organic farming were also tested. We found that sucrose: fructose ratio was lower in organic fruits. Weather conditions were unfavorable in 2019 for strawberry production therefore sugar concentrations were much lower than expected.
\end{abstract}

\section{Introduction}

Based on WHO data, 60 million people suffers diabetes in Europe [14]. In Hungary $13 \%$ of adults and $0.27 \%$ of children (0-18 years old) are diabetic, based on 2017 data [10]. Sugar content and composition is especially important for diabetic patients, and people with insulin resistance. Glycemic index of strawberry is relatively low. The favorable distribution of carbohydrates (content of sucrose is low while the content of fructose is higher) makes it edible for diabetics as well. Total sugar content of strawberry fruits is about $8.6 \mathrm{~g} / 100 \mathrm{~g}$ [3].

Organic acids are important health-protecting components. Consumption of organic acids has a metabolic stimulating effect and it can reduce the complaints of people suffering from gout or rheumatism [4]. On the other side, people who react sensitively to fruit acids - and also breastfeeding mothers - might prefer fruits with low acid concentrations [4].

Results on the nutrient value of fruits grown organically versus conventionally are contradictory. In the publications comparing organic versus conventional conditions, farms are on different locations, and therefore weather conditions, soil type etc. are different, so it is difficult to separate the effects of the many complex factors [7] [13]. To get reliable picture on the differences, as a first step we applied an experimental design, where on the same location different nutrient supply methods (inorganic versus organic fertilizers) were applied. In a series of experiments we compare the yield and quality (dry matter content, macro- and microelements, sugar, acid, antioxidant, etc.) of strawberry fruits applying organic versus inorganic nutrient supply.

Later on further factors will be tested. If we can approach the yields of conventional farming and prove that nutrient values and health-promoting compounds exceed those of conventional fruits, it may be worth considering organic strawberry production, as it can be consumed as "functional food".

\footnotetext{
* Corresponding author. Tel.: +36 76 517696;

E-mail address: mihalka.virag@kvk.uni-neumann.hu
} 
In the present work, we compare the most important sugar and organic acid compounds of fruits, harvested in the year of planting.

Algae biostimulants improve photosynthetic activity, therefore they might increase carbohydrate content of strawberry. PGPR bacteria help nutrient intake of plants on a number of way, which can stimulate their biochemical pathways, their metabolism [11], [12]. Because of the above reasons and because microbial products are more and more used in organic crop production [5], two microbial products were involved in the experiment.

\section{Material and Methods}

\subsection{Experimental set up, cultivar, planting, culture conditions}

Our experiment was set up at the Experimental Garden of the Faculty of Horticulture and Rural Development of John von Neumann University (Kecskemét, Hungary). Fragaria $\times$ ananassa 'Asia' frigo seedlings were planted on $26^{\text {th }}$ of March 2019 in a twin-row arrangement $\left(30{ }^{*} 25 \mathrm{~cm}+60 \mathrm{~cm}\right.$ cultivation path). 4 twin rows plus one- one single row on both sides were planted. $8 \mathrm{~m}{ }^{*} 4 \mathrm{~m}$ area, treatments were separated by $0.5 \mathrm{~m}$ fallow strips.

4 different culture conditions (nutrient supply were tested):

- ORG: organic fertilizers were applied

- ORG+B: organic fertilizers + Bacterial inoculation

- $\mathrm{ORG}+\mathrm{B}+\mathrm{A}$ : organic fertilizers + Bacterial inoculation + Alga suspension

- CONV: inorganic fertilizers

Basic fertilization and nutrient replenishment were planned based on soil analysis. As this is a comparative experiment, the nutrient replenishment was designed so, that approximately the same amount of nitrogen and potassium would be applied in the organic and conventional fields. Accordingly, a total of $233 \mathrm{~kg} /$ ha of Haifa Turbo and $125 \mathrm{~kg} /$ ha of granular potassium sulphate was applied to the conventional plot, while $700 \mathrm{~kg} / \mathrm{ha}$ of Phoenix pelleted poultry manure was applied to the organical area, so that the same amounts of nitrogen and potassium were applied. Irrigation was performed with a microspray irrigation system.

Due to several weeks of rain in early May, fungal control became necessary. On 31 May, copper-containing foliar fertilizer (Scudo) preparation was applied at a concentration of $2 \mathrm{ml} / \mathrm{l}$.

\subsection{Bacterial inoculations}

On one plot a bacterial soil inoculant (BactoFil B-10) was applied (ORG+B). The product was diluted with tap water, sprayed on the soil and worked in immediately. Inoculation was executed directly before planting. Besides, $100 \mathrm{ml}$ of 5000 x diluted BactoFil B-10 was poured in every planting hole, right before planting of frigo transplants.

\subsection{Treatment with alga suspension}

A microbial product (Algafix), containing Scenedesmus obtusiusculus cells was diluted with tap water and sprayed on the plants in $2 \mathrm{l} /$ ha quantity at the beginning of flowering.

\subsection{Chemicals applied for analysis}

Citric acid (98\% purity), malic acid (95\% purity), tartaric acid ( $96 \%$ purity), succinic acid ( $99 \%$ purity), glucose (99,5\% purity), fructose (99\% purity), sucrose $(99,5 \%$ purity) were purchased from Sigma-Aldrich. Sulfuric acid (98\%) was purchased from Merck. The high purity water was produced in the analytical laboratory of Széchenyi István University.

\subsection{Sample preparation}

Fruits were picked randomly from 20-20 plants / treatment. In order to avoid border effect, no samples were taken from the single rows. For the extraction, raw samples were used. As a first step, the fruits were washed and the parts suitable for human consumption chopped with a kitchen chopper (Old Smith) (parts size less than $1 \mathrm{~mm}$ ) and then standardized. 
Samples were measured using precision tare balance (Denver Istrument, type APX-3202). 11 grams of samples (3-3 parallel measurements per sample) were weighed into $250 \mathrm{ml}$ Erlenmeyer flasks and $50 \mathrm{ml}$ of high purity water was added.

Extraction was performed using 358 S-type (Elpan) laboratory shaker. Samples were shaken for one hour, and $10 \mathrm{ml}$ of each sample were put into a $15 \mathrm{ml}$ centrifuge tube. The centrifugation was performed with a Z $206 \mathrm{~A}$ type centrifuge (Hermle) at $6000 \mathrm{rpm}$ for $30 \mathrm{~min}$.

After centrifugation, $1-1 \mathrm{ml}$ of supernatants were filtered into $1.8 \mathrm{ml}$ screw capped vials trough $0.22 \mu \mathrm{m}$ hydrophilic syringe filter.

\subsection{HPLC analysis}

\subsubsection{Analysis of organic acids}

The organic acids were analyzed by ion exclusion chromatography, with a Jasco HPLC system (Jasco LC-900 series). A Bio-Rad Aminex HPX-87H column was used to separate the constituents. The column temperature was $35^{\circ} \mathrm{C}$. $0.1 \%$ sulfuric acid was used as eluent and the flow rate was 0.5 $\mathrm{ml} / \mathrm{min}$. The detection wave-length was $210 \mathrm{~nm}$.

\subsubsection{Analysis of sugars}

Sugar contents were analyzed by ion exclusion chromatography, using the Jasco HPLC system (Jasco LC-900 series). Supercogel H type (Sigma-Aldrich) column used for the separation at room temperature. High purity water was used as eluent with a flow rate of $0.5 \mathrm{ml} /$ minute. Refractive index detector was used to determine the quality and quantity of the components.

\section{Results and Discussion}

\subsection{Organic acid content of fruits}

Concentrations of 4 organic acids (malic acid, citric acid, tartaric acid and succinic acid) were measured. In our samples no tartaric and succinic acid were found. Concentrations of malic and citric acids are summarized in Table 1.

Table 1. Organic acid concentrations of strawberry fruits grown organically versus conventionally in $\mathrm{mg}$ / $\mathrm{g}$ fresh weight. Means \pm Standard deviations, $n=3$. The different treatments marked as:

ORG: nutrient supply according to organic farming B: organic farming+BactoFil B-10 treatment $B+A$ : organic farming + BactoFil B-10 and Algafix treatments, CONV: conventional.

\begin{tabular}{lll}
\hline mg/g FW & Malic acid & Citric acid \\
\hline \hline ORG & $1.89 \pm 0.05$ & $6.64 \pm 0.28$ \\
ORG $+B$ & $1.35 \pm 0.14$ & $5.59 \pm 0.29$ \\
ORG $+B+A$ & $2.15 \pm 0.13$ & $5.29 \pm 0.13$ \\
CONV & $0.75 \pm 0.1$ & $6.67 \pm 0.19$
\end{tabular}

Our results are similar to the values published in the nutrition and nutrients composition book of [3]. We found that malic acid concentrations varied between 1.18 and $2.29 \mathrm{mg} / \mathrm{g}$, while they published that general malic acid content of strawberry is about $1.5 \mathrm{mg} / \mathrm{g}$. Concentrations for citric acid varied between 5.2 and $6.92 \mathrm{mg} / \mathrm{g}$, while Bíró-Lindner [3] published the general value of $5 \mathrm{mg} /$ $\mathrm{g}$ for strawberry. Neither tartaric nor succinic acids were detected in the samples, though based on the Bíró-Lindner book [3]., general tartaric acid content of strawberry is about $0.6 \mathrm{mg} / \mathrm{g}$. Organic acid concentrations showed no clear correlations with the applied treatments. 


\subsection{Carbohydrates of fruits}

As the most abundant sugars in strawberry are glucose, fructose and sucrose [1] [3], our study focused on these carbohydrates.

Our results showed higher glucose, fructose and total sugar while lower sucrose level in fruits of organically-grown strawberry plants. We found no clear effect of the applied microbial products on carbohydrate levels.

In the literature, we find contradictory data on whether there is a significant difference in the carbohydrate composition and concentrations of organic versus conventional fruits. Cayuela et al., [6] and Conti et al., [7] found higher sugar content in organic fruits of strawberry, while others found no significant differences [8], [9] [13].

Table. 2. Average sugar concentrations of organically versus conventionally grown strawberry fruits. Means \pm Standard deviations, $n=3$. The different treatments marked as: ORG: nutrient supply according to organic farming B: organic farming + BactoFil B-10 treatment $\mathbf{B}+\boldsymbol{A}$ : organic farming+ BactoFil B-10 and Algafix

CONV: conventional $n=3$

\begin{tabular}{|c|c|c|c|c|}
\hline (mg / $\boldsymbol{g}$ FW) & Glucose & Fructose & \multicolumn{1}{l|}{ Sucrose } & Total \\
\hline$O R G$ & $13.04 \pm 0.384$ & $17.53 \pm 0.497$ & $0.127 \pm 0.114$ & 30.697 \\
\hline$O R G+B$ & $7.791 \pm 0.757$ & $11.35 \pm 0.973$ & $0.076 \pm 0.065$ & 19.217 \\
\hline$O R G+B+A$ & $8.278 \pm 1.157$ & $10.87 \pm 1.479$ & $0.063 \pm 0.339$ & 19.211 \\
\hline CONV & $5.737 \pm 1.033$ & $9.252 \pm 1.655$ & $0.272 \pm 0.188$ & 15.261 \\
\hline
\end{tabular}

As regards sucrose, our results are consistent with the findings of Akšić and co-workers. They found that organically-grown fruits contain less sucrose [1]. In our experiments sucrose: fructose ratio was about 0.01 in organic while 0.03 in conventional fruits. These findings are interesting, but carbohydrate metabolism and accumulation is very complicated and multi-factorial process, therefore we have to be careful when drawing conclusions.

One of the main factors influencing the nutritional composition of fruits is the maturation stage of the fruit. The carbohydrate concentrations measured in our study (Table 1.) are far below the concentrations known from literature. In the nutrition and nutrients composition book from BíróLindner reference values for the different carbohydrates are 2-3 fold higher [3] compered to our results.

For correct interpretation of these data we have to take into account that 2019 was an extremely problematic year for strawberry cultivation. Large amounts of precipitation and the lack of sunshine in the ripening period caused problems. Constant humidity favored the occurrence of fungal diseases. Our plantation showed symptoms of Phytophthora and Colletotrichum fragariae, which resulted in significant stem destruction and an average yield loss of $16-32 \%$ (data not shown).

Due to the rainy weather and the poor sunshine period, we could observe that the nutritional parameters of the fruits did not develop favorably. This can be one of the reasons why our results on the different carbohydrate concentrations remain below the expected values for strawberries [1], [2] [9].

On other reason for the low carbohydrate concentrations could be, that as we did not want to lose more fruits due to fungal disease we probably picked fruits too early. As strawberry is a nonclimacteric fruit has to be picked at full maturity. So in this case they could not reach the full maturity and therefore the nutritional and sensory qualities were not able to develop. Hopefully the results of the next growing- season will be more reliable.

\section{Conclusion}

When interpreting the results, we have to take into account, that differences in the content of fruit produced under organic and conventional farming conditions are a consequence of several years of organic farming, thanks to healthy ecosystems in the area and soil microbiomes. Nutrient 
supply is only one component of the different, complex factors effecting quality of fruits. 2019 growing season was extremely problematic for strawberry production, weather conditions, and fungal diseases influenced our results. It is expected that we will get more reliable results in the coming years.

\section{Acknowledgment}

Thank you for the support of the research carried out in the framework of the EFOP-3.6.2-162017-00012 „Developing a functional, healthy and safe food product chain model from field to table in a thematic research network". The project is funded by the Hungarian State and the European Union, co-financed by the European Social Fund, and is part of the Széchenyi 2020 program.

\section{References}

[1] Akšić, M. F., Tosti, T., Sredojević, M., Milivojević, J., Meland, M., \& Natić, M. (2019). Comparison of sugar profile between leaves and fruits of blueberry and strawberry cultivars grown in organic and integrated production system. Plants, 8(7), 205.

[2] Basu, A., Nguyen, A., Betts, N. M., \& Lyons, T. J. (2014). Strawberry as a functional food: an evidence-based review. Critical reviews in food science and nutrition, 54(6), 790-806. DOI: 10.1080/10408398.2011.608174

[3] Bíró Gy- Lindner K (1999): Táplálkozástan és tápanyag-összetétel. Medicina, Budapest

[4] Hecke, K., Herbinger, K., Veberič, R., Trobec, M., Toplak, H., Štampar, F., ... \& Grill, D. (2006). Sugar-, acidand phenol contents in apple cultivars from organic and integrated fruit cultivation. European Journal of Clinical Nutrition, 60(9), 1136-1140. DOI: 10.1038/sj.ejcn.1602430

[5] De Pascale, S., Rouphael, Y., \& Colla, G. (2017). Plant biostimulants: innovative tool for enhancing plant nutrition in organic farming. Eur. J. Hortic. Sci, 82(6), 277-285. DOI: 10.17660/eJHS.2017/82.6.2

[6] Cayuela, J. A., Vidueira, J. M., Albi, M. A., \& Gutiérrez, F. (1997). Influence of the ecological cultivation of strawberries (Fragariax Ananassa Cv. Chandler) on the quality of the fruit and on their capacity for conservation. Journal of agricultural and food chemistry, 45(5), 1736-1740. DOI: 10.1021/jf960745h

[7] Conti, S., Villari, G., Faugno, S., Melchionna, G., Somma, S., \& Caruso, G. (2014). Effects of organic vs. conventional farming system on yield and quality of strawberry grown as an annual or biennial crop in southern Italy. Scientia Horticulturae, 180, 63-71. DOI: 10.1016/j.scienta.2014.10.015

[8] Hargreaves, J. C., Adl, M. S., Warman, P. R., \& Rupasinghe, H. V. (2008). The effects of organic and conventional nutrient amendments on strawberry cultivation: Fruit yield and quality. Journal of the Science of Food and Agriculture, 88(15), 2669-2675. DOI:10.1002/jsfa.3388

[9] Kallio, H., Hakala, M., Pelkkikangas, A. et al. Sugars and acids of strawberry varieties. Eur Food Res Technol 212, 81-85 (2000). DOI: 10.1007/s002170000244

[10] KSH: Health conditions (2004-2018) https://www.ksh.hu/thm/2/indi2_8_1.html (2020.05.02)

[11] Matics, H. and Biró, B. (2015): History of soil fertility enhancement with inoculation methods. Journal of Central European Agriculture 16 (2): 231-248. DOI: 10.5513/JCEA01/16.2

[12] Menendez, E., \& Garcia-Fraile, P. (2017). Plant probiotic bacteria: solutions to feed the world. AIMS microbiology, 3(3), 502-524. DOI: 10.3934/microbiol.2017.3.502

[13] Reganold JP, Andrews PK, Reeve JR, Carpenter-Boggs L, Schadt CW, et al. (2010): Fruit and Soil Quality of Organic and Conventional Strawberry Agroecosystems. PLOS ONE 5(9): 1-14. DOI: 10.1371/journal.pone.0012346

[14] WHO: Health Topics http://www.euro.who.int/en/health-topics/noncommunicable-diseases/diabetes/data-andstatistics (2020.05.02) 